\title{
Conflicts in the investigation and treatment of sexually abused children
}

\section{Danya Glaser}

This paper examines the complex relationship between the process of investigation and the provision of treatment in cases of child sexual abuse. Child sexual abuse is now a well-recognised and documented phenomenon, the deleterious sequelae of which have been studied, initially in survivors presenting in adulthood (Wyatt \& Powell, 1989) and (more recently) during childhood (Briere, 1992; Kendall-Tackett et al, 1993). Following the recognition of sexual abuse from the accounts of adult survivors, and in order to reduce the harm caused to sexually abused children by providing earlier protection and treatment, attention began to be directed to the earlier recognition of child sexual abuse, during childhood.

True primary prevention of child sexual abuse is likely to be very difficult to achieve for the majority of potential victims. A degree of secondary prevention could be achieved through the active and effective protection of those children who are likely to come into contact with known or suspected sexual abusers of children. In the current context, even this limited aim is unlikely to be realised, since the rate of denial of abuse by alleged abusers is very high (Glaser \& Spencer, 1990). New measures are being implemented to register all known 'schedule one' offenders, that is, those convicted of offences against children (see pp. 70-76, this issue). However, since only a minority of sexual abusers are convicted, this measure will achieve very partial protection. Teaching children to protect themselves by increasing their awareness of child sexual abuse and encouraging them not to keep secrets is a further form of secondary protection. For these reasons, child protective intervention will continue to need to focus on tertiary prevention, that is the prevention of further abuse, early detection of established abuse and treatment designed to minimise the harmful consequences of abuse that has already occurred (Box 1).

Except in acute assaults, the 'natural history' of much sexual abuse is a progression from 'grooming' behaviour by the abuser towards the child, moving on to non-penetrative touching of genitalia and enforced masturbation and finally leading on to oral, vaginal and/or anal penetration. Investigation that results in early detection is, therefore, particularly important since there is evidence to show that duration and frequency of abuse are positively related to poor outcome for adult survivors (Tsai $\mathcal{E}$ Wagner, 1979).

\section{Investigation}

Investigation is now part of well-defined procedures dealing with suspicions of child sexual abuse (Department of Health, 1995). The investigation has several purposes: child protection, prosecution, therapy.

An investigation of suspicion of child sexual abuse is required in order to enable a process of child protection to be set in motion in those cases

Box 1. Difficult aspects of child protection

Primary prevention is unlikely to be achieved

There is some possibility of protecting vulnerable children

Protection is mainly in the form of protection from prolonged abuse or further abuse

Danya Glaser is a consultant child and adolescent psychiatrist at Great Ormond Street Hospital (London WC1N3JH). She has a long-standing interest in various forms of child abuse and neglect. This has included extensive clinical work with all aspects of sexual abuse, emotional abuse and factitious illness, the interface between adult mental health and child protection, and work on the interaction between the law and child mental health. 
where there is an indication that a child is unprotected from abuse.

Furthermore, investigation of child sexual abuse aims to serve the public interest by bringing abusers to justice. This aspect of the fulfillment of public interest has several functions including: the protection of potential victims in the future; punishment of, or retribution towards, the offender; and deterrence of other potential abusers.

The content of the investigation also lays the foundations for delineating the therapeutic needs for the child and the family.

There are several areas of concern during the investigation in cases of suspected child sexual abuse.

\section{Peri-abuse factors}

The primary aim of the investigation is to establish whether abuse has occurred and, if so, to establish who the abuser was and the nature of the relationship between the abuser and the child. The investigation will also establish the nature, duration and circumstances of the abuse.

\section{Pre-abuse factors}

A full investigation will provide some information about events and family experiences pre-dating the abuse. In particular, it is important to establish the degree and nature of any pre-existing vulnerability of the child, such as neglect or rejection, and the nature of the care-giving relationships in the child's family.

\section{Post-abuse factors}

Information is also required about the nature of the responses by the child's primary carers to the discovery of abuse - whether the child is believed, supported and actively protected, or not believed and blamed for the allegation. The prognosis for a child who has been sexually abused is directly related to the non-abusing carer's (often the mother's) response. The closer the relationship between the mother or primary carer to the alleged abuser, the worse is the child's situation.

\section{Triggers of the investigation}

One starting point of the investigation may be a child's description of abuse, termed a disclosure in recognition of the (usually) secret nature of child sexual abuse. Other starting points include more or less specific aspects of the child's behaviour or physical state (see Fig. 1). Specific physical symptoms and signs suggestive of, or compatible with, sexual abuse include sudden onset of genital soreness, unexplained vaginal bleeding, a sexually transmitted disease or pregnancy in a young girl where the father is unknown. They are, however, found in less than $50 \%$ of children who have been sexually abused. Behaviour suggestive of sexual abuse includes, in particular, sexualised behaviour that is age-inappropriate or compulsive in nature. Children known to have been in unsupervised contact with recognised sexual abusers may also be suspected of having been abused. There are other, less specific, indicators that may lead to the suspicion of sexual abuse. They include, in particular, a change in the child's behaviour and emotional state (Glaser \& Frosh, 1993).

\section{The child's account}

Owing to the almost invariable absence of conclusive physical evidence and the fact that sexual abuse is rarely witnessed, evidence of abuse rests heavily on the child's description and occasionally on the confession of an abuser. The child's word and description are therefore subjected to very careful scrutiny (Coulborn-Fuller \& Corwin, 1995). This

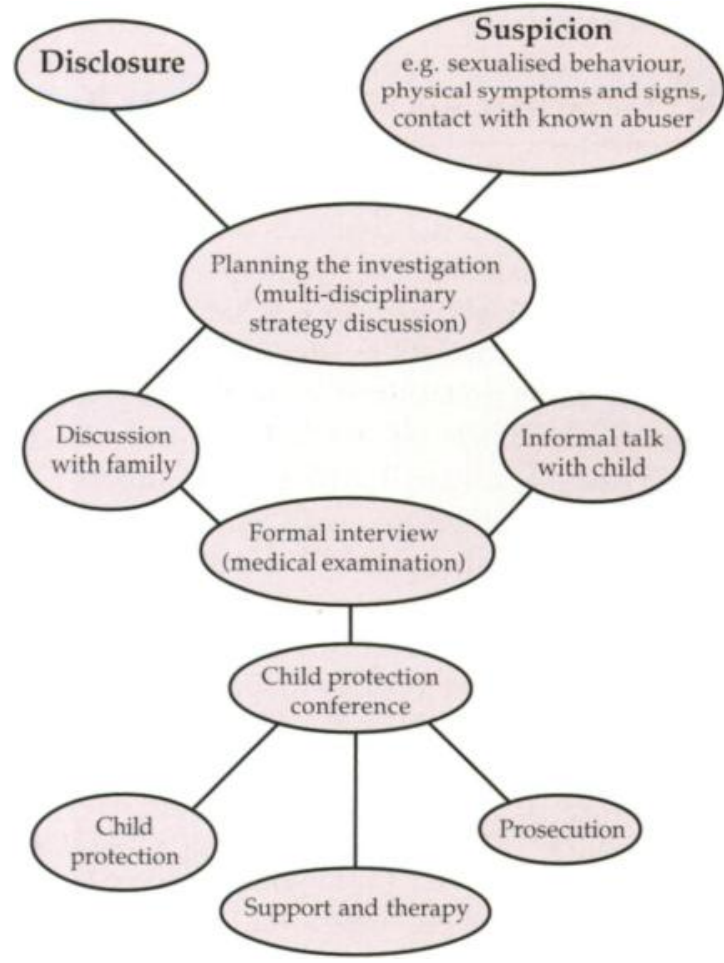

Fig. 1 Pathways from suspicion to resolution 
includes a careful examination of the sequence of events which led to suspicions or concern about the possibility of sexual abuse, the contents and context of the child's first description and a search for possible motivations for the child to have given a false account. There is inevitably a search for the possibility that the child might have been induced into giving a false account, through leading questions and suggestions to the child that abuse has occurred. There is some empirical evidence indicating that, in non-traumatised children below the age of seven, repeated questioning and suggestion may lead the children to acquire false beliefs to which they will adhere even when subsequently presented with contrary evidence (Ceci \& Bruck, 1993). Other research has shown children to be resilient to false suggestions concerning their own experiences (Tobey \& Goodman, 1992). There has therefore been a move towards minimising the number of times a child is questioned. The wish to avoid repeated questioning of children is also based on concerns about children's discomfort at being required to repeat accounts of stressful experiences.

These considerations have led to well-established guidelines for the process of video-recording single (or exceptionally, repeated) formal interviews of children (Home Office \& Department of Health, 1992). These interviews are carried out jointly by trained social workers and police child protection officers, reflecting the dual needs and interests of the child protection and criminal justice systems.

\section{Use of video-recorded evidence}

\section{In a criminal trial}

The video-recorded interview may be used as the prosecution's evidence in cases of child abuse which reach a criminal trial and in which the alleged abuser pleads not guilty (Criminal Justice Act 1991).

\section{In a civil hearing}

Children's accounts of abuse also form an important part of the evidence in civil legal proceedings both in private and in public law. In the former, as part of divorce proceedings, there may be disputes about future contact between the child(ren) and their nonresident parent, when the latter is suspected of sexual abuse. In public law, significant harm (Adcock et al, 1991) and child protection are at issue. Hearsay descriptions of the child's account, which are permissible in civil cases, as well as a viewing of a video-recorded interview, form part of the evidence, and help the judge to make a finding in relation to the likelihood of abuse having occurred. Such a finding has significant implications for the child's future, although it has no legal bearing on the fate of the alleged abuser.

\section{Presenting the child's account to the alleged abuser}

An alleged abuser who knows of and may be shown the video-recorded evidence may then admit the abuse, and change his plea to guilty, thus relieving the child of the need to be crossexamined at the trial (Davies et al, 1995).

\section{Helping the non-abusive carer hear the child's account}

A proportion of mothers or other primary carers who had previously found difficulty in believing the child's allegation in the face of an outright denial by the alleged abuser, will come to believe the child when witnessing the child's description on video. The less 'led' the child is, the more credence is likely to be given to the child's account.

\section{Conflict between investigation and therapy}

A seemingly smooth path is thus laid out, leading sequentially from suspicion or spontaneous description of abuse, through to investigation. If this indicates that abuse is likely to have occurred, the need for child protection, therapy and a possible prosecution will then be considered (Department of Health, 1995). This pathway suggests that treatment for the consequences of child sexual abuse should follow an investigation which has indicated that abuse has taken place. Why then, might investigation and therapy come into conflict with each other? There are several issues which, in practice, lead to considerable potential and sometimes actual conflict between the needs of investigation and the needs for, and of, treatment.

\section{Therapeutic v. investigative interviews}

As already indicated, there are, on the one hand, clearly defined procedures and agendas for 
investigative interviews, whose rigors have been instituted to allow the outcome to be presented as evidence, particularly in the criminal courts. On the other hand, as part of the treatment process, therapeutic interviews may well seek new and salient information about the child's experiences as a way of enabling the child to describe the source of their distress, gain relief from, and control over, the burden of traumatic memories and lead to an understanding of the child's difficulties. Unlike the investigative interview, the therapeutic process permits and, indeed, encourages the use of nonverbal, symbolic play and drawing as modes of communication for the child. The therapeutic process is also less constrained by time requirements, allowing for several interviews or for a longer-term treatment process.

\section{Symptomatic child who has not disclosed abuse}

There are children who present with various, more or less specific indicators of sexual abuse requiring treatment, but who have described abuse neither spontaneously, nor in response to questioning. Some of these children are severely emotionally traumatised, confused and frightened and others have harmed themselves deliberately. Some children present with sexualised behaviour, extending at times to abusing other children. They require treatment to alleviate their distress and to reduce their troubling symptoms. In the course of this treatment, accounts of abuse may emerge. This may become important if the child is subsequently considered to require protection, or if the child describes abuse also affecting other children who may remain unprotected.

What is the evidential status of any disclosures of abuse that emerge during the therapeutic process? Should all such therapeutic work with children, who may have been abused, be videorecorded? While this may be desirable from a legal stance, it is not practicable. There is, however, a need for a careful written record to be made as soon as possible after each session with the child.

\section{Unexpected suspicion arising in the course of therapy}

In the course of individual or, occasionally, family therapy that is unrelated to known sexual abuse, the therapist may become suspicious or aware of the possibility of sexual abuse of the child. This may arise as a result of descriptions made by the child or remarks about, for instance, not liking to be with a particular person. Observed family interactions may show an emotionally neglected child or be based on, for instance, highly sexualised content of play or behaviour which begins to emerge during treatment.

Difficult decisions then face the therapist and these need to be discussed with a trusted colleagues or the team, prior to further action. This discussion centres around the likely meaning and validity of interpretations of the observed behaviours and descriptions and how to proceed. There are questions about timing, with the relative risks of leaving a child unprotected versus the premature or unjustified initiation of an investigation. The latter will inevitably affect the therapeutic process, probably adversely. It is difficult to quantify the level of suspicion. The principle, therefore, needs to be that if there is consensus between colleagues that suspicion is warranted, the matter should be pursued.

Should the therapist pursue their suspicions directly with the child, or should the suspicions be reported to investigating agencies such as social services? This is a difficult question which requires some discretion. Reporting to social services will require naming the concerns to the parents and may possibly lead to the silencing of the child, if sexual abuse was known about and concealed. However, it is possible that an initial investigation by social services might yield confirmatory information. There is a further possibility of initially consulting with social services without naming the family, and together planning the initial inquiry by the therapeutic agency already involved. The principle that often applies is that the agency or person holding the initial suspicion is in the best position to pursue the suspicion or concern. This does, however, constitute a change of mode or direction in the work with the child and family, and it is important that if the change is perceptible, it is acknowledged to them as the pursuance of an explanation for a particular concern.

At whatever point social services are informed, if a child has not described sexually abusive experiences, then precipitous formal, investigative interviewing is not advisable, since younger children in particular are unlikely to give a clear description of abuse in a formal interview unless they have previously spoken about the abuse in a familiar and informal setting (details available from the author upon request; see Box 2). Therefore, if the suspicion is based on the child's behaviour or disturbed emotional state, an explanation for this must be sought separately from the parents and from the child. It is not advisable at this stage to mention sexual abuse explicitly. If the child has 
Box 2. Unexpected suspicion arising from therapy

Need to pursue explanation for suspicion

The person holding the suspicion is often the best person to pursue it

Young children are far more likely to repeat a description of abuse in a formal interview if they have previously done so informally

played or behaved in a sexual and age-inappropriate way, or shown preoccupation with sexual matters, it is necessary to explore with the child the origins of this preoccupation, but stopping short of specific enquiries about experiences of sexual abuse. The therapist is not usually the appropriate professional to go on to conduct the formal investigative interview (Furniss, 1991), should a need for this be subsequently indicated.

\section{Relationship between therapy and investigation}

When an investigation concludes that a child has been abused and reliable protection for the child has been achieved, the next requisite step in the process of psychological recovery for the child and the family may well be some form of therapeutic work (Glaser, 1991). This may include individual or group work for the child and the carer(s) and family work may also be indicated. However, in order to ensure the child's long-term interests, therapeutic and clinical considerations need to take into account any impending legal proceedings. Therapy that commences before a criminal trial may be regarded by the court as prejudicial to the outcome of the trial. Therapy which precedes a full hearing in the civil court may be regarded as unwarranted pre-emption of the court's decision in the case.

\section{Relationship between therapy and legal proceedings}

\section{Controversy of pre-trial therapy}

There are often legal concerns that therapy might 'contaminate' a child's evidence.

Although the child's early video-taped statement forms a significant part of the case for the prosecution in cases of alleged child sexual abuse, the child is currently still required to attend the trial for cross-examination by the defence. There has been concern that possible distortion of the child's recollection might occur in the period between the initial video-recorded interview and the trial, especially if the child was receiving therapy. Specifically, the concern has been about the possibility of suggested false information and belief about the abuse being adopted by the child during the course of therapy. Group therapy, in which a child is likely to hear the accounts of other children's abuse, has been singled out for special concern. While from a criminal and legal point of view such concern is understandable, it has led to much debate about the fact that such considerations deprive children of much-needed therapy. Clearly, if a child is very troubled or distressed and deemed to be in urgent need of psychiatric help, clinical considerations take precedence over legal ones, even if the implication is the abandonment of the prosecution.

The Memorandum of Good Practice (Home Office \& Department of Health, 1992) acknowledges the possible need for therapy and recommends prior consultation with the Crown Prosecution Service (CPS). In practice, there has been considerable variation country-wide in the advice given by the CPS, leading to child witnesses often having to await therapy until after the trial is completed. This poses uncomfortable choices for abused children and their carers. While they might be anxious for the child to give evidence in court, this means that a child may need to postpone the relief that therapy is designed to achieve, particularly if the child suffers from post-traumatic phenomena.

This dilemma would be resolved if there were not the inordinate delay of many months before the trial takes place. This delay is caused partly by the need to gather full information in preparation for the trial, and partly by organisational difficulties in the courts. There have been some attempts at fast-tracking of cases involving children as witnesses, but difficulties have been encountered with this approach. An alternative solution, and one which is being widely recommended for various reasons including the reduction of delay, is the full implementation of the Pigot Committee Report (1989) recommendations (Royal College of Psychiatrists, 1996). This would allow a child witness to give evidence and be cross-examined at an early, preliminary hearing, which would take place before the judge designated to hear the full trial. This preliminary hearing would, in turn, be video-recorded, to be shown to the jury at the full trial. Since the child would not thereafter be needed in court, therapy could commence.

\section{Therapy before civil proceedings}

Similar difficulties to those described for criminal legal proceedings may arise if a child who is 
believed to have been sexually abused is known to be the subject of impending civil proceedings, either in private or public law. The considerations are, however, different. Criminal legal proceedings are concerned with establishing beyond reasonable doubt whether it is the alleged abuser who has abused the child. The person of interest is the defendant and the child is a mere witness with no legal rights. Civil proceedings are an extension of the investigation that seeks to establish whether the child has been abused and, if possible to establish, by whom. The emphasis is on the child's experience, about which a finding will be made by the judge, on the balance of probabilities.

A situation may arise in which professionals, including child psychiatrists, involved with the child, believe that a child has been abused but the judge at a hearing fails to make a finding. Such an outcome may mean that this child is then returned to the care of a parent who does not believe that the child has been abused. Under these circumstances, it is unethical to offer post-abuse treatment to the child. Furthermore, there has been some criticism from judges, of treatment that has commenced prior to the outcome of the trial, suggesting a tension between clinical and legal considerations. The irony is that both these processes set out to fulfill the needs of children.

\section{Can civil proceedings always be foreseen?}

All cases involving child abuse may potentially find their way to civil legal proceedings, either because the child is thought to need a court order to achieve sufficient protection, or because the allegations subsequently become a part of matrimonial and contact disputes (Tjaden \& Thoennes, 1992). However, at the time of referral to child mental health services, there may be no indication that later proceedings may take place. For instance, a father who had been alleged to have abused a child, denied the allegation and moved out of the family home may, at a later date, apply for contact with the child. At this point, he may commence proceedings, sometime after the child had already received therapy for the consequences of the sexual abuse.

There is a distinction between the process of investigation and, if needed, immediate protection, and the provision of post-protection treatment. Responsibility for the former has been vested jointly in social services and the police. Child mental health services play a significant role in the latter, although they often play a consultative part in the former (Royal College of Psychiatrists, 1993). It would be impractical and inappropriate for child psychiatrists to repeat the investigation which must have preceded the referral of a child for therapy (see Box 3). However, implicit in the position taken

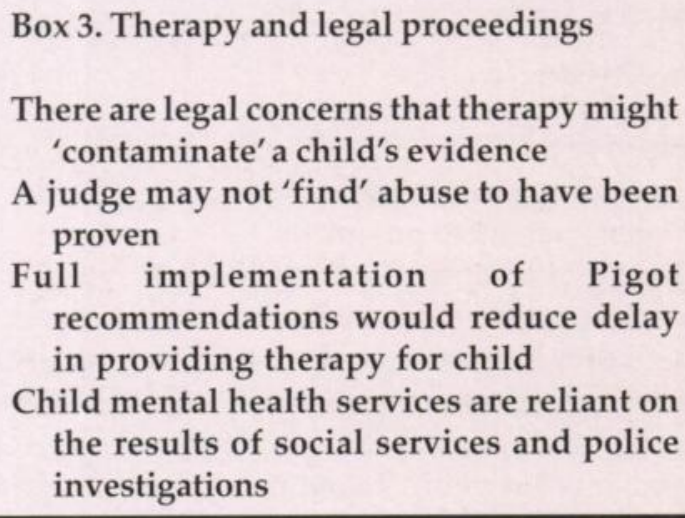

by the judiciary is the suggestion, that there is a need for a very careful scrutiny of the facts that have led to the decision regarding the likelihood of abuse. Child mental health services are therefore advised to obtain a full report from social services about the conclusions of their investigation and they might also benefit from viewing any video-recorded interview with the child. As part of the assessment for treatment, it is important to meet with the child, the carer and the family. It may also be appropriate to meet separately with the alleged abuser, if only to evaluate the (not infrequent) denial of the abuse, and to gauge the nature of the relationship between the abuser and the family.

\section{Conflict and balance of interests}

Children's interests may fall between the considerations governing various legal processes on the one hand, and therapeutic requirements on the other. A continuous dialogue between clinicians and law-makers is an important way of ensuring that the interests of children do not become lost.

\section{References}

Adcock, M., White, R. \& Hollows, A. (eds) (1991) Significant Harm. London: Significant Publications.

Briere, J. (1992) Child Abuse Trauma - Theory and Treatment of Lasting Effects. London:Sage.

Ceci, C. \& Bruck, M. (1993) Suggestibility of the child witness. A historical review and synthesis. Psychological Bulletin, 113, 403-409.

Coulborn-Fuller, K. \& Corwin, D. (1995) Children's interview statements and behaviours: role in identifying sexually abused children. Child Abuse and Neglect, 19, 71-82.

Davies, G., Wilson, C., Mitchell, R., et al (1995) Videotaping Children's Evidence: An Evaluation. London: Home Office. 
Department of Health (1995) The Challenge of Partnership in Child Protection: Practice Guide. London: HMSO.

Furniss, T. (1991) The Multi-Professional Handbook of Child Sexual Abuse. London: Routledge.

Glaser, D. (1991) Treatment issues in child sexual abuse. British Journal of Psychiatry, 159, 769-782.

- \& Spencer, J. (1990) Sentencing children's evidence and children's trauma. Criminal Law Review, June, 371-382.

— \& Frosh, S. (1993) Child Sexual Abuse. London: Macmillan.

Home Office \& Department of Health (1992) Memorandum of Good Practice on Video Recorded Interviews with Child Witnesses for Criminal Proceedings. London: HMSO.

Kendall-Tackett, K., Williams, L. \& Fenkelhor, D. (1993) Impact of sexual abuse on children: a review and synthesis of recent empirical studies. Psychological Bulletin, 113, 164-180.

Pigot, T. (Chairman) (1989) Report of the Advisory Group on Video Evidence. London: Home Office.

Royal College of Psychiatrists (1993) Child Psychiatry and Child Sexual Abuse, Council Report CR24. London: Royal College of Psychiatrists.

- (1996) The Evidence of Children, Council Report CR44. London: Royal College of Psychiatrists.

Tobey, A. \& Goodman, G. (1992) Children's eyewitness memory: Effects of participation and forensic context. Child Abuse and Neglect, 16, 779-796.

Tjaden, P. \& Thoennes, N. (1992) Predictors in legal intervention in child maltreatment cases. Child Abuse and Neglect, 16, 807-821.

Tsai, M. \& Wagner, N. (1979) Therapy groups for women sexually molested as children. Archives of Sexual Behaviour, 7, 417-427.

Wyatt, G. \& Powell, G. (eds) (1989) Lasting Effects of Child Sexual Abuse. London: Sage.

\section{Multiple choice questions}

1. In the context of fuller public and professional awareness of child sexual abuse:

a primary prevention is now a real possibility

b most protection only happens after some abuse has already taken place

c the proposed register of 'schedule one' offenders will protect most children from sexual abuse

d prosecution of alleged abusers is now always part of the child protection process.

2. The following considerations are true for good practice in formal interviewing of children by police and social services:

a all children suspected of having been sexually abused, should be immediately interviewed by police and social services

b when a child is suspected of having been abused, repeated formal investigative interviews are recommended to enable the child to describe abuse accurately

c children are more likely to describe abuse in a formal interview if they have previously talked to a familiar person about the abuse

d for evidential reasons, open and non-leading questions are preferable.

3. If a child is going to give evidence at a criminal trial, then:

a therapy for an abused child should not be contemplated prior to the child giving evidence

b the trial judge's permission must be awaited before therapy is offered to any abused child

c group therapy for sexually abused girls is best postponed until after the child has given evidence

d a child's video-recorded description of abuse is positively associated with a plea of not guilty by the alleged abuser.

4. If therapeutic services are to fulfill the child's best interests, then:

a if there are limited resources, some need to be earmarked for work with the mother to enhance her belief and active protection of the child

b all children who have been abused require psychotherapy

c a therapist who suspects that a child has been abused should immediately inform the parents

d group work with children who have been sexually abused is particularly indicated.

\begin{tabular}{|cclll|}
\hline \multicolumn{2}{|c|}{ MCQ answers } & & \\
1 & 2 & 3 & 4 \\
a F & a F & a F & a T \\
b F & b F & b F & b F \\
c T & c T & c T & c F \\
d F & d T & d F & d T \\
\hline
\end{tabular}

